\title{
Potentially serious side-effects of high-dose twice-weekly rifampicin*
}

\author{
Graham Poole
}

Peter Stradling

\author{
SHEILA WoRLLEDGE \\ Chest Clinic and Department of Haematology, Royal Postgraduate Medical School, \\ and Hammersmith Hospital, DuCane Road, London, W.12
}

\begin{abstract}
Summary
Daily rifampicin in a single dose of $600 \mathrm{mg}$, combined with other drugs, usually streptomycin and isoniazid, was given to forty-nine patients for 3 months. It was planned to continue for another 15 months with twice-weekly rifampicin $1200 \mathrm{mg}$ plus isoniazid 900 mg, but the high incidence of side effects led to cessation of the intermittent regimen when only two patients had completed 18 months.

Though there was no serious problem with daily treatment, eleven patients $(22 \%)$ were unable to continue rifampicin on the intermittent regimen. In eight $(16 \%)$ a pyrexial syndrome occurred. In one of these patients there was also temporary renal failure and in another, precipitous thrombocytopenia led to epistaxis and bleeding into the tongue and lips. Symptomless thrombocytopenia developed in two other patients, making three cases $(6 \%)$ of thrombocytopenia in all.

In sixteen $(33 \%)$ of the forty-nine patients antibodies to rifampicin were detected in the blood. Sideeffects occurred in nine $(56 \%)$ of these, including the three developing thrombocytopenia, but in only two $(6 \%)$ of the thirty-three patients with no antibodies detected. This association of toxic reactions with antibodies is highly significant $(P<0.001)$.
\end{abstract}

\section{Introduction}

Laboratory reports on rifampicin suggest that it is one of the most effective anti-tuberculosis drugs yet discovered (Verbist \& Gyselen, 1968) and clinical results are highly encouraging (Gyselen et al., 1969). The only significant side-effect reported when the drug is used on a daily basis is jaundice, which is particularly likely to occur in alcoholics (Lesobre et al., 1969; Lees et al., 1970). Laboratory work further suggests that rifampicin should be highly effective in intermittent regimens (Batten, 1969; Grumbach, Canetti \& Le Lirzin, 1969; Dickinson \& Mitchison, 1970).

We started a clinical trial of intermittent rifampi-

* This article is reprinted from the British Medical Journal (1971) 3, 343-347, by kind permission of the Editor, cin therapy in the summer of 1969. This preliminary report on side-effects of rifampicin is made to warn

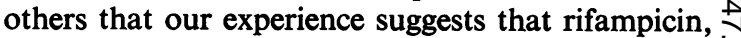
when used twice-weekly at a dosage of $1200 \mathrm{mg}$, can or result in an unacceptably high incidence of toxicity. $\omega$ One side-effect encountered (thrombocytopenia) is $\mathrm{N}$ potentially extremely serious and was first recog-o

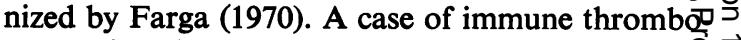
cytopenia with rifampicin antibodies detected bi $\vec{Z}$ reaction with platelets and red cells has already beep reported from this school (Blajchman et al., 197 and two more have now occurred, together with case of transient renal failure.

\section{Materials and methods}

\section{Regimen}

The trial regimen planned, and used in most cases, was intra-muscular streptomycin $0.75 \mathrm{~g}$, oral isoniazıd $300 \mathrm{mg}$, and oral rifampicin $600 \mathrm{mg}$ on 6 days a week for 3 months, followed by twice-weekly rifampicin $1200 \mathrm{mg}$, with isoniazid $900 \mathrm{mg}$, plus pyridoxin $10 \mathrm{mg}$, for a further 15 months. Appropriate dosage adjustments were made for the two children in the series. Administration of all doses to all patients was fully supervised.

\section{Patients}

All newly-diagnosed tuberculous patients with tuberculosis attending the Chest Clinic at Hammer- $\dot{\delta}$ smith Hospital from 1 July, 1969 were considered 3 for inclusion in the trial. Also included in this toxicity 0 study were three patients who received, for retreatment of relapsed disease, regimens including rifam- $\frac{D}{2}$ picin plus ethambutol and, as a third drug, either isoniazid, streptomycin or capreomycin. New o patients with alcoholism, proved liver disease, or N pregnancy, or who were only temporarily resident in the area, were not treated with rifampicin. In $\sigma$ addition, two patients were not included because they were receiving large doses of steroid and $\stackrel{0}{\frac{D}{D}}$ immuno-suppressive therapy, after renal transplant $\stackrel{\oplus}{\rightarrow}$ 
operations, which may well have materially altered the response to rifampicin.

The report includes only those patients who had completed at least 4 months of treatment, the range being from 4 to 18 months: only two patients completed the planned 18 months.

The forty-nine patients in the survey (thirty-three males and sixteen females aged 9-84 years) came from various racial groups (Tables 1 and 2). Immigrants accounted for $61 \%$ (Asians and Negroes, $37 \%$; Caucasians, $24 \%$ ).

Thirty-seven patients with tuberculosis attending other units and receiving drugs other than rifampicin were used as controls (thirty males and seven females). The age and racial distribution was similar to that in the rifampicin group: immigrants again comprised $61 \%$.

\section{Toxicity precautions}

If pregnancy occurred during treatment rifampicin was stopped. Bilibrubin, alkaline phosphatase and isocitric dehydrogenase estimations were done routinely on pretreatment blood samples, and again 3-4 weeks after treatment had started. Patients were also warned to report any untoward symptoms, particularly nausea, itching or aching in the upper abdomen. Inquiries for any possible toxic symptoms were routinely made by the nurses administering the treatment and the eyes were examined regularly for jaundice. Hepato-toxicity is not considered further here, except to state that no patients developing the side-effects described in this paper suffered hepatotoxic reactions.

Table 1. Age and sex distribution of the patients treated with rifampicin

\begin{tabular}{|c|c|c|c|}
\hline Age groups & Males & Females & Totals \\
\hline $9-20$ & 2 & 1 (1) & 3 (1) \\
\hline $21-30$ & 6 (4) & 2 (1) & 8 (5) \\
\hline $31-40$ & 8 (2) & 3 (1) & 11 (3) \\
\hline $41-50$ & 7 & 5 (3) & 12 (3) \\
\hline $51-60$ & 9 (1) & 2 (1) & 11 (2) \\
\hline $61+$ & 1 & 3 (2) & 4 (2) \\
\hline Totals & $33(7)$ & $16(9)$ & 49 (16) \\
\hline
\end{tabular}

The number of patients developing rifampicin-dependent antibodies is shown in parentheses.

TABLE 2. Country of origin of the patients treated with rifampicin

British Irish Asian African W. Indian Other European

\begin{tabular}{llllll}
\hline $19(6)$ & $7(2)$ & $6(1)$ & 1 & $11(6)$ & $5(1)$ \\
\hline
\end{tabular}

The number of patients developing rifampicin-dependent antibodies is shown in parentheses.

\section{Direct antiglobulin tests}

These were carried out as a screening procedure by testing the patient's red blood cells with a broadspectrum antiglobulin serum used in two dilutions. The dilutions chosen were those that had previously been determined as optimal for detecting complement and IgG respectively when bound to the red cells. Any positive results were further tested by standard techniques with an anti-IgG serum, an anti-IgM serum, an anti-IgA serum and an anticomplement serum (Dacie \& Lewis, 1968).

\section{Indirect antiglobulin tests}

These were also carried out as a screening procedure, the method described by Harris (1956) being used. A total of $70 \mathrm{mg}$ of purified rifampicin (kindly supplied by Professor D. A. Mitchison), or the rifampicin from the capsules, was dissolved in $100 \mathrm{ml}$ of $0.95 \%$ sodium chloride and added to an equal volume of the patient's serum. (There was no difference in the results when using either of these two solutions of rifampicin.) The tests were read with a broad-spectrum antiglobulin serum used in the two dilutions described above. In a control test saline was substituted for rifampicin. The $\mathrm{pH}$ activities of the rifampicin solution and the saline were the same.

The serum for all the indirect antiglobulin tests was separated from the red cells within $4 \mathrm{hr}$ of taking the sample. The serum was either tested at once or frozen to $-20^{\circ} \mathrm{C}$ and tested within $24 \mathrm{hr}$. The normal red cells used in the screening procedure were the group $\mathbf{O}$ red cells that are prepared daily in our laboratory for the detection of atypical blood group antibodies.

\section{Haematological tests}

Platelet complement fixation tests were carried out as previously described (Blajchman et al., 1970). The patients in the rifampicin group had full blood counts, including platelet estimations, done at monthly intervals. Two samples were taken each time; one just before the rifampicin was given and one $6 \mathrm{hr}$ later.

\section{Results}

All the patients on rifampicin did remarkably well clinically. There were thirty-seven $(76 \%)$ from whom Mycobacterium tuberculosis was isolated: thirtythree $(89 \%)$ converted in 8 weeks, and all in 24 weeks. The majority accepted rifampicin with equinimity on a daily basis during the initial 3 months. The situation became very different, however, during the subsequent intermittent regimen.

A total of eleven patients $(22 \%)$ were unable to continue rifampicin because of side-effects develop- 
ing on intermittent treatment. These side-effects were of two types: firstly, a febrile reaction occurring in eight $(16 \%)$ patients and secondly, thrombocytopenia occurring in three $(6 \%)$. (One patient had both the febrile reaction and thrombocytopenia.) Another patient complained of persistent nausea and slight malaise, but did not suffer the febrile reaction or other symptoms.

\section{The febrile reaction}

This clinical syndrome has become clearly recognizable and has been established as directly due to rifampicin by administering $600 \mathrm{mg}$ trial doses of this drug alone to each patient. Pyrexia $\left(99-105^{\circ} \mathrm{F}\right)(37 \cdot 2-$ $40.5^{\circ} \mathrm{C}$ ) for up to $24 \mathrm{hr}$ and malaise occurred in all eight patients at $2 \frac{1}{2}-4 \mathrm{hr}$ after the dose. Rigors occurred in seven; nausea occurred in three with vomiting in two; and myalgia was prominent in two. A sharp rise in blood pressure occurred in two patients (from $130 / 80$ to $240 / 130 \mathrm{mmHg}$ in one and from $180 / 110$ to $220 / 140 \mathrm{mmHg}$ in the other). The first of these had temporary renal failure (blood urea $270 \mathrm{mg} / 100 \mathrm{ml}$ ) but responded in a few days to methyldopa and diuretics. Whether the renal failure was a result of an antigen-antibody reaction or a direct toxic effect of the drug or consequent upon dehydration due to the vomiting is not known. The last explanation seems improbable on clinical grounds.

\section{Thrombocytopenia}

Thrombocytopenia occurred in three patients $(6 \%)$. One case already reported (Blajchman et al., 1970 ), presented with epistaxis and bleeding into the lips and tongue; in the other two, the monthly determinations of the platelet levels showed drugrelated platelet falls but without symptoms. The platelet level fell, after trial doses of rifampicin, from 147,000 to $29,000 \mathrm{~mm}^{3}$ and from 120,000 to $12,000 \mathrm{~mm}^{3}$ respectively; rifampicin was therefore withdrawn in spite of the absence of symptoms.

\section{Direct antiglobulin test}

The red cells of the patient with thrombocytopenia whose case was previously reported gave a moderately strong positive direct antiglobulin test. However, the red cells of the other two patients who developed symptomless falls in their platelet counts did not show significantly positive results. It has been previously shown that the red cells in $8 \%$ of samples from hospital patients give weakly positive results in this test (Dacie \& Worlledge, 1969). Similar results were found when the red cells of this series of patients were tested. These positive results, which were not consistently present in any one patient, did not correlate in any way with the presence or absence of symptoms, and this test was abandoned as a routine procedure half-way through the investigation.

\section{Indirect antiglobulin test}

By using the serum from patients on rifampicin, $c$. this test gave a positive result in the presence of rifampicin, but not in its absence, in sixteen patients $(33 \%)$. It did not give a similar positive result in any sera from patients in the control group. Further tests with the sera of patients who gave rifampicindependent positive reactions showed that the positive results were due to complement components bound to the red cell surface. It was presumed that this complement had been bound by rifampicin antibodies in the presence of the drug. These rifampicindependent antibodies did not show any blood group specificity; provided the drug was also present they reacted equally well with the patient's own cells and with each of the red cell samples from seven donors specially chosen to reveal blood group specificity.

In five patients rifampicin-dependent antibodies were detected in the serum taken on one occasion only; samples were not available for further tests. The sera from the remaining eleven patients gave positive results with samples taken on more than ong $z$ occasion and several patients were sampled manf times. The average number of samples taken from the patients on rifampicin, both with and withou antibodies, was four. Samples were taken from the control patients on only one occasion.

The sera of three of the forty-nine patients o rifampicin contained atypical blood group ant bodies and gave positive results in the indirect antiglobulin test with both added rifampicin and added saline. The sera of three of the thirty-seven patients in the control group reacted in the same way (Table 3). These antibodies all had the specificity of antiLewis. Patients with blood group antibodies were retested for rifampicin antibodies with Le(a-b-)red cells.

TABLE 3. Results of testing the serum of patients suffering from tuberculosis for antibodies. The tests were done by the indirect antiglobulin technique with normal red cells both in the presence and in the absence of excess rifampicin

\begin{tabular}{lcc}
\hline & $\begin{array}{c}\text { Rifampicin } \\
\text { included in not included } \\
\text { regimen }\end{array}$ & $\begin{array}{c}\text { Rifampicin } \\
\text { in regimen }\end{array}$ \\
\hline Total no. of patients & 49 & 37 \\
No. with rifampicin-dependent & $16(33 \%)$ & 0 \\
antibodies & 3 & 3 \\
No. with blood group antibodies & 3 & \\
\hline
\end{tabular}

\section{Platelet complement fixation test}

This test was positive when the serum of the patient with thrombocytopenia previously reported $\frac{0}{\mathscr{C}}$ was used. However, the sera of the two other $\stackrel{0}{\rightarrow}$ 
patients, who developed symptomless falls in their platelet count, did not show positive results. Similarly, no positive reactions were obtained in this test with the sera from any of the other patients.

\section{Rifampicin-dependent antibodies and clinical features}

Rifampicin-dependent antibodies were detected in sixteen patients $(33 \%)$ : they occurred in all the age groups (Table 1). There is a suggestion that females developed antibodies more readily than males $(56 \%$, $P<0.01$ and $21 \%, P<0.05)$. The antibodies also appeared whatever the patient's country of origin, apparently more often in West Indians (Table 2).

TABLE 4. Association between the occurrence of side-effects in the patients and the detection of rifampicin-dependent antibodies in their sera

\begin{tabular}{crrr}
\hline & \multicolumn{2}{c}{ Side-effects } & Total \\
\cline { 2 - 3 } & Present & Absent & \\
\hline Antibodies & & & \\
Present & 9 & 7 & 16 \\
Absent & 2 & 31 & 33 \\
Total & 11 & 38 & 49 \\
\hline
\end{tabular}

As is evident from Table 4, side-effects occurred in nine $(56 \%)$ of the sixteen patients with antibodies, but in only two $(6 \%)$ of the thirty-three patients with no antibodies detected. This association is highly significant $(P<0.001)$. In Fig. 1 the side-effects are related to the month of treatment at which these effects first appeared and the time of detection of the rifampicin-dependent antibodies. Of the two patients in whom no antibodies were detected, one had the typical febrile syndrome and one complained of nausea only. In five patients antibodies were found the first time the patient was tested. In four patients

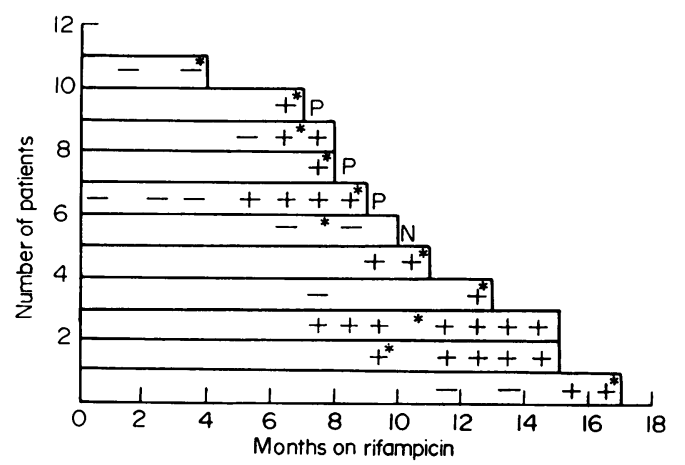

FIG. 1. Duration of treatment in eleven patients with side-effects and relates the month of treatment in which these side-effects first appeared $\left(^{*}\right)$ to the presence $(+)$ or absence $(-)$ of rifampicin antibodies. The three patients who developed thrombocytopenia are indicated by $\mathrm{P}$; the one patient who developed nausea only is indicated by $\mathrm{N}$.

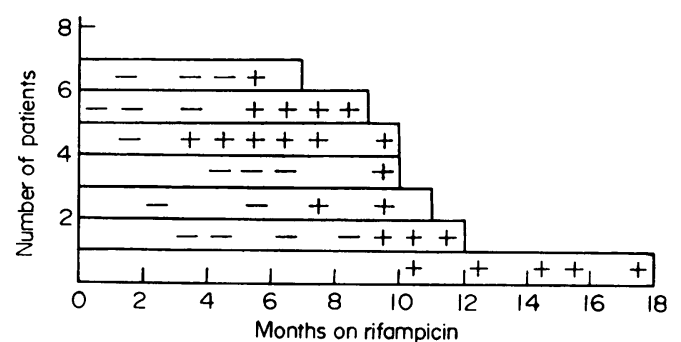

FIG. 2. Duration of treatment in the seven patients with antibody but no side-effects. + indicates presence,

- indicates the absence of rifampicin antibodies.

the first tests were negative and antibodies appeared later. It will be seen that antibodies could appear before the onset of side-effects.

In Fig. 2 the length of treatment is related to the time of detection of rifampicin-dependent antibodies in the sera of the patients without side-effects. Antibodies were detected in one patient the first time the serum was tested. Antibodies appeared in the serum of the other six patients after a variable length of time. There is no relationship between the length of time of treatment and the development of rifampicindependent antibodies except that none were detected before the fourth month of treatment-that is, after starting the intermittent regimen. A comparison of the doses that patients received on a $\mathrm{mg} / \mathrm{kg}$ body-weight basis with the presence or absence of antibodies oblique side-effects showed no relationship within this relatively narrow dose range (13-26 $\mathrm{mg} / \mathrm{kg}$ body weight).

There was no direct correlation between the antibody titres and the presence or absence of symptoms. Symptoms appeared in two patients who had low titres of antibody ( 2 and 2 ), and one patient having a higher titre (32) did not complain of symptoms.

\section{Discussion}

Our short clinical experience with the forty-nine patients here reported supports previous opinions that rifampicin is a very valuable drug of great effectivity and of low toxicity when used on a daily basis at $600 \mathrm{mg}$. When used twice-weekly in $1200 \mathrm{mg}$ doses, however, it is clearly potentially extremely dangerous. One-third of our patients, all on the intermittent regimen, developed antibodies to the drug even though very few of them had yet been exposed to a full course of treatment. Eleven $(22 \%)$ suffered some form of side-effect leading to a withdrawal of the drug. A pyrexial syndrome, sometimes severe and once complicated by transient renal failure, developed in eight $(16 \%)$; in only one of these were antibodies not detected. Three patients $(6 \%)$, one of whom also had pyrexia (Blajchman et al., 1970), and all of whom had antibodies, developed thrombocytopenia. 
Reports from Chile first drew attention to thrombocytopenia occurring during treatment with large, intermittent doses of rifampicin (Farga, 1970), while Burghard \& Petitjean (1970) reported purpuric rashes with positive Shelley tests to rifampicin. Larbaoui et al. (1970) observed one patient with generalized purpura thought to be due to 4 months of treatment with rifampicin. Doyle et al. (1969) have also found a high incidence of sideeffects (twenty-eight of seventy-four patients, including six with fever) when rifampicin was given in high dosage $(1800 \mathrm{mg})$ twice-weekly. These results compare very unfavourably with the comparable efficacy but lower toxicity, and much lower cost, of either thrice-weekly streptomycin plus isoniazid (Poole \& Stradling, 1965, 1969), or twice-weekly streptomycin plus isoniazid (Polansky, 1970; Stradling \& Poole, 1970) over a 15-month period following 3 months of daily treatment. The trial undertaken in Madras of intermittent streptomycin plus isoniazid, given continuously from the start of treatment, also revealed a low incidence of side-effects and high efficiency (Tuberculosis Chemotherapy Centre, Madras, 1964; Ramakrishnan et al., 1969).

In the present series a variety of drugs other than rifampicin were being taken by patients in the rifampicin and control groups. These included streptomycin, isoniazid, para-amino-salicylic acid and ethambutol. There was no relation between these drugs and the presence or absence of rifampicin-dependent antibodies.

Rifampicin-dependent antibodies appeared more frequently in females than in males but the numbers are too small to permit definite conclusions. Similarly, no relation between the incidence of these antibodies and the racial origin of the patients, their age, or the small variations in weight/dose relationship, can be deduced from these small numbers. There was no pattern in the time of detection except that none were found before the fourth month of treatment when all the patients had already started high-dose intermittent rifampicin. Since these antibodies could be detected for the first time as late as the sixteenth month of treatment, it is clear that, if the treatment had continued, additional patients would probably have produced them and perhaps dangerous side-effects.

The rifampicin-dependent antibodies bound complement to the surface of the patient's own or normal red cells in the presence of the drug. None of the patients, however, showed any evidence of red cell haemolysis in vivo. In a paper describing a case of immune thrombocytopenia due to quinine, Croft and his colleagues (1968) showed that the drugrelated antibody could be easily detected in vitro by an indirect antiglobulin test when using red cells in the presence of the drug, even though their patient, like ours, showed no haemolysis in vivo. Presumably $\stackrel{0}{0}$ the amount of complement bound to the red cells in the presence of pharmacological amounts of the $z$ drug was insufficient to lead to increased red cell $\stackrel{\mathbb{2}}{\complement}$ destruction.

Several drugs are known to cause thrombocyto- $\overrightarrow{\bar{F}}$ penia by an immunological mechanism; these include stibophen, quinidine, quinine and apronal. In the three patients in the present series with thrombocytopenia we were able to detect comple- $\underset{\mathbb{D}}{\overparen{D}}$ ment-consumption in the presence of normal $\stackrel{\mathbb{Q}}{\square}$ platelets and the drug in only one. However, the complement fixation test in which platelets were $\overrightarrow{0}$ used has been shown to be less sensitive than the cytotoxic test where lymphocytes were used in the $\vec{\omega}$ detection of platelet and white cell antigens (Svejgaard, Kjerbe \& Kissmeyer-Nielsen, 1967) and this lack of positive results may well be due only to the lack of sensitivity of the method.

The precise steps in the evolution of the drug- of induced antibodies is uncertain, but it has been postulated that the drug acts as a hapten, which, after it has bound to macromolecules in the plasma 0 becomes antigenic and stimulates antibody forma tion. Furthermore, this hypothesis suggests that the $\vec{Z}$ antibodies are directed against the drug and that 1 i the drug is given again hapten-antibody complexes will be formed. These hapten-antibody complex may either bind complement in the blood streang which perhaps could lead to the febrile reactions, $\vec{Q} \vec{\varphi}$ be absorbed to the membrane of blood cells (reeg. cells and platelets) and there bind complement. It complement bound to the surface of the platelets that is thought to lead to their destruction.

We have found no reports of thrombocytopenia in patients receiving daily treatment with rifampicin. It seems likely that either the larger dose or the twice-weekly regimen or both determine or increase the immunological process.

There may well be a critical upper level of permissible dosage, exceeded in our series, below which the drug can be given safely and effectively on an intermittent basis. The finding that only small increases in dose can raise the serum concentration to disproportionately high levels (Canetti et al., 1968) is pertinent in this context and encourages trials of intermittent regimens in which doses lower than $1200 \mathrm{mg}$ are used. A preliminary report by Decroix et al. (1969), of results with a $900 \mathrm{mg}$ twice-weekly dose of rifampicin is very encouraging.

It is to be hoped that further large-scale trials of $N$ rifampicin, particularly those under the auspices of $N$ the British Medical Research Council, will elucidate the problems posed by our findings and determine an effective, safe dose to use in intermittent regimens. Meanwhile we feel unable to continue to use rifampicin at a dose of $1200 \mathrm{mg}$ twice-weekly. 


\section{Acknowledgments}

We acknowledge the expert technical assistance of Miss Eleanor Lloyd and Mrs Irene Owen, and the constructive suggestions of Professor D. A. Mitchison and Professor J. V. Dacie. Miss Angela Hartog and Miss Margaret Oliver helped with the collection of clinical data. The medical staff of the Willesden Chest Clinic, the Central Middlesex Hospital, St Charles's Hospital and the Brompton Hospital kindly gave permission for patients under their care to act as controls. Dr M. A. Thomson collected most of the control samples. Dr M. A. Blajchman helped considerably with the early investigations. Miss P. Gammon estimated the actual content of the rifampicin solution. Lepetit Pharmaceuticals Ltd generously supplied the rifampicin and a grant for technical assistance. Drs Bergamini and Granger, of Lepetit Ltd provided much valuable information.

\section{References}

Batten, J. (1969) Tubercle (Lond.), 50, 294.

Blajchman, M.A., Lowry, R.C., Pettit, J.E. \& Stradling, P. (1970) British Medical Journal, 3, 24.

Burghard, G. \& Petitjean, R. (1970) Journal de Medicine de Strasbourg, 1, 79.

Canetti, G., Le Lirzin, M., Porven, G., Rist, N. \& GrumBACH, F. (1968) Tubercle (Lond.), 49, 367.

Croft, J.D., Swisher, S.N., Gilliland, B.C., Bakemeier, R.F., LEDDY, J.E. \& WEED, R.I. (1968) Annals of Internal Medicine, 68, 176.

Dacie, J.V. \& Lewis, S.M. (1968) Practical Haematology, 4th edn. J. \& A. Churchill, London.

Dacie, J.V. \& Worlledge, S.M. (1969) In: Progress in Hematology (Ed. by E. B. Brown and C. V. Moore), Vol. 6. Grune and Stratton, New York.

Decroix, G., Kreis, B., Sors, Ch., Birembaum, J., Le LiRzin, M. \& CANETti, G. (1969) Revue de la Tuberculose et de Pneumologie (Paris), 33, 751.

Dickinson, J.M. \& Mitchison, D.A. (1970) Tubercle (Lond.), $51,82$.
Doyle, J.A., Rodriguez, E., LAmbertini, A., Bronchisi, B.A., Dolman, A., Simon, J. \& Lopez, J.A. (1969) $X X$ International Tuberculosis Conference, New York, p. 25. Published for Lepetit by Excerpta Medica.

FARGa, V. (1970) Personal communication.

Grumbach, F., Canetti, G. \& Le Lirzin, M. (1969) Tubercle (Lond.), 50, 280.

Gyselen, A., Verbist, L., Cosemans, J., Lacquet, L.M., Prignot, J., Simon-Pouthier, F., Debrabandère, R. \& DEVRIENDT, J. (1969) Acta tuberculosea et pneumologica, $60,563$.

HARRIS, J.W. (1956) Journal of Laboratory and Clinical Medicine, 47, 760.

Larbaoui, D., Chaulet, P., Grosset, J., Abderrahim, K., Oussedik, N., Coucke, Ch. \& Benabdallah, L. (1970) Revue de Tuberculose et de Pneumologie (Paris), 34, 559.

Lees, A.W., Asgher, B., Hasham, M.A. \& Sinhar, B.N. (1970) British Journal of Diseases of the Chest, 64, 90.

Lesobre, R., Ruffinn, J., Teyssier, L., Achard, F. \& Brefort, G. (1969) Revue de la Tuberculose et de Pneumologie (Paris), 33, 393.

Polansky, F. (1970) Bulletin of the International Union Against Tuberculosis, 43, 295.

Poole, G.W. \& Stradling, P. (1965) Tubercle (Lond.), 46, 290.

Poole, G.W. \& Stradling, P. (1969) British Medical Journal, 1, 82.

Ramakrishnan, C.V., Devadatta, S., Evans, C., Fox, W., Menon, N.K., NAZARETh, O., Radhakrishna, S., Sambamoorthy, S., Stott, H., Tripathy, S.P. \& Velu, S. (1969) Tubercle (Lond.), 50, 115.

Stradling, P. \& Poole, G.W. (1970) Tubercle (Lond.), 51, 44.

SvejgaARd, A., KJerbe, K.E. \& Kissmeyer-Nielsen, F. (1967) In: Histocompatibility Testing (Ed. by E. S. Curtoni, P. L. Mattinz and R. M. Tosi). Munksgaard, Copenhagen.

Tuberculosis Chemotherapy Centre, MAdras (1964) Bulletin of the World Health Organisation, 31, 247.

Verbist, L. \& GySELEN, A. (1968) American Review of Respiratory Diseases, 98, 923. 